\title{
Comparitive Analysis of DV-hop and APIT Localization Techniques in WSN
}

\author{
Ravneet Kaur ${ }^{1}$ and Jyoteesh Malhotra ${ }^{2}$ \\ ECE Department, GNDU Regional Campus, Jalandhar, Punjab, India ${ }^{1,2}$ \\ ravneetkaur4141@gmail.com ${ }^{1}$, vinitdhaliwal@gmail.com ${ }^{2}$
}

\begin{abstract}
New advancements in wireless sensor networks (WSNs) make it a significant technology in research and academic community. Because of its ad-hoc and minimum infrastructure nature, it has gained lot of attention by researchers in past few years. In WSN, sensor nodes are small sized with limited energy processors which have most important task in WSN. They gather data, process it and further send it to the destination. In many applications like rescue operations, military tracking, environment monitoring etc. it is required that location of sensors must be known else the information collected gets no meaning. So, many localization algorithms are introduced in WSN which meet the resource, hardware, cost and energy constraints of WSN. Range free localization techniques are best suited for these requirements of network. DV-HOP and APIT range free techniques have gained attention in most of research efforts. So,in this paper ,performance of these techniques is evaluated on the basis of accuracy obtained while implementeing them in WSN. Detail analysis of localization error is done by considering different network parameters effecting it directly. Further structured deployment of anchors is proposed that gave more reliable results.
\end{abstract}

Keywords: Localization, DV-HOP localization Algorithm, APIT Localization algorithm, Localization error

\section{Introduction}

Recent advancements in semiconductors, communication [10] and networking technologies are driving pervasive deployment of large scale wireless sensor networks (WSNs). Due to availability of tiny, cheap and smart sensors and appropriate RF circuitry for data transmission, WSN has become one of the most promising technologies [3]. WSN is formed using very small but capable sensors that sense, gather and transmit the information to a large network of such sensors. There are pronounced applications of WSN, like providing faster warnings from disasters, fine-spun observations of the surrounding environment, performing more efficient agriculture, all with important economic significance. Similarly, applications in battle field surveillance, healthcare or habitat and structural monitoring help to increase our daily welfare. Localization is one of the most important key techniques in WSN because the location knowledge of sensors is helpful in most of the applications i.e. for coverage, placement, routing, location service, target tracking, and rescue. Hence, location evaluation is a demanding technical challenge for researchers and academic community [9]. So, it is highly desirable to design cost effective, scalable, efficient and reliable localization mechanisms for WSNs. These sensor node localization schemes [8] have different features used for different applications. Localization methods are broadly categorized into two categories: Range based and Range free localization techniques [11]. Range based techniques [4] use range measurements like received signal strength [12], angle of arrival and time of arrival for location estimation whereas Range free methods omit the use of range measurement techniques, instead network topology and connectivity information is used to find the 
location of sensors placed in the network. Therefore,range free techniques overpower the range based techniques in terms of lesser power consumption, low cost, no extra hardware, less installation and computational complexity [5]. In return,these features of Range free techniques have attracted a lot of research efforts in recent years. In this paper we have implemented DV-HOP[1],[2] and APIT[7][6] using MATLAB ${ }^{\mathrm{TM}}$.The results are being analysed for various network parameters under random and uniform placement strategy of sensor nodes in the network for DV-HOP and APIT individually in sections 3and 4 respectively. After achieving best suitable network parameters for both the techniques, comparison is further extended by proposing a structured deployment strategy of anchors .Using second and third order error analysis tools ,the detail analysis is reported in section 5. Analysis based conclusion is drawn in section 6 .

\section{Simulation Methodology and Environment}

Among the main range free localization techniques-Centroid,DV-HOP,APIT and MDS-MAP. DV-HOP is one of the techniques that brought a dramatic change in the fashion of localization by considering multi hop sensor nodes in the network after a simple centroid technique. APIT, then considered area based approach in localization of sensors in WSN with much improvement in reliability of technique. So, these two techniques are yet to be explored by researchers.we have implemented these techniques in $\mathrm{MATLAB}^{\mathrm{TM}}$.Simulations are done assuming certain parameters and setup environment as shown below in table 1:

Table 1. Simulation Setup

\begin{tabular}{|r|c|c|}
\hline S.no. & Parameters & Specifications \\
\hline 1. & Area & 100x100 square area \\
\hline 2. & Sensor nodes \\
\hline 3. & Total nodes & 100 \\
\hline 4. & Anchor nodes & 8 \\
\hline 5. & Unknown nodes & 92 \\
\hline 6. & $\begin{array}{c}\text { Placement strategies of } \\
\text { Anchor nodes }\end{array}$ & $\begin{array}{c}\text { Random, Uniform, Square } \\
\text { Regular }\end{array}$ \\
\hline 7. & Radio Ranges & $25-50 \mathrm{~m}$ \\
\hline 8. & Simulations done & 300 \\
\hline
\end{tabular}

As shown in table 1, area of $100 \times 100$ sq.units is taken and the total of 100 sensor nodes of which 8 are anchor nods and 92 are unknown nodes are deployed in a way that they are connected to each other to form a network.

\subsection{Network Scenarios}

Deployment strategy of these sensor nodes are varied to form 3 types of scenariosRandom deployment, Uniform deployment, Square Regular deployment.

2.1.1. Random Deployment: Unknown sensor nodes are distributed in random fashion and also the anchors are placed randomly as shown in figure 1 below. 


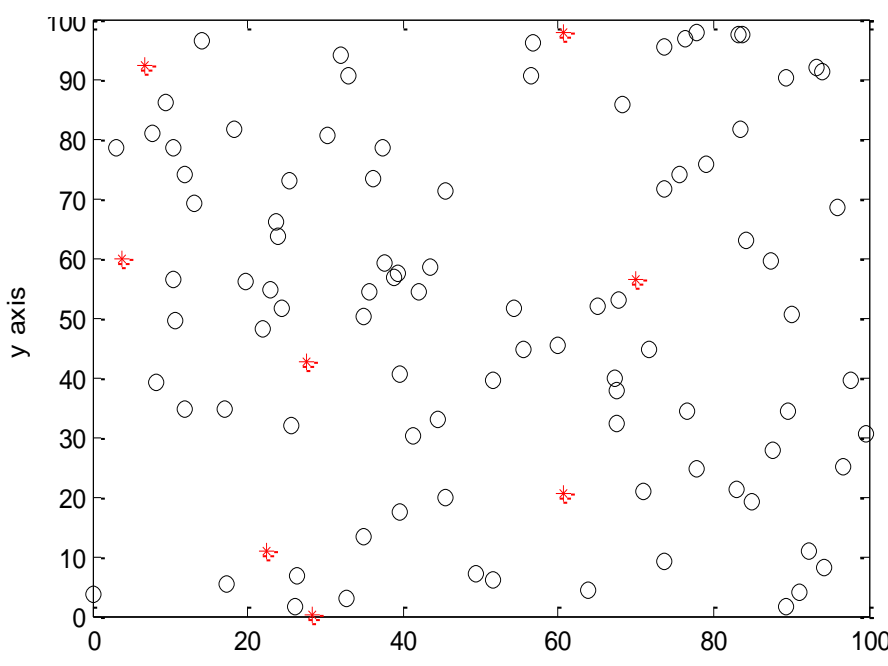

Red-Anchors,

Black-Unknown

Figure 1. Random Placement Model

2.1.2. Uniform Deployment: Unknown nodes and anchor nodes are deployed randomly but the whole area is divided into grids to place the sensors at equal distances. This is shown in the Figure 2 below:

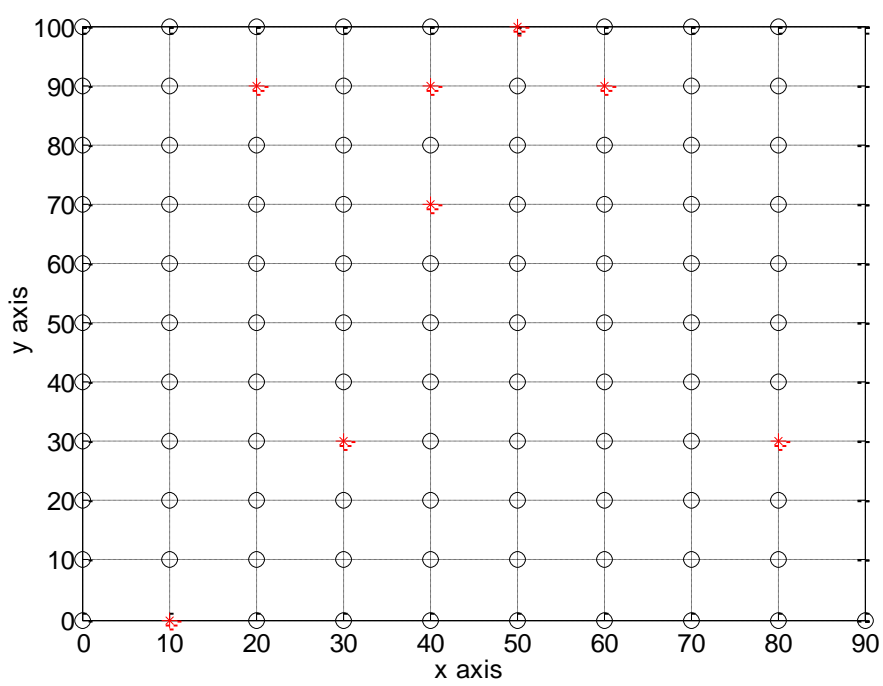

Red-Anchors,

Black -Unknown

Figure 2. Uniform Placement Model

2.1.3. Square Regular Deployment: Unknown nodes are placed randomly at the corners of grids and the anchors are placed in concentric squares to form a regular network as shown in Figure 3. 


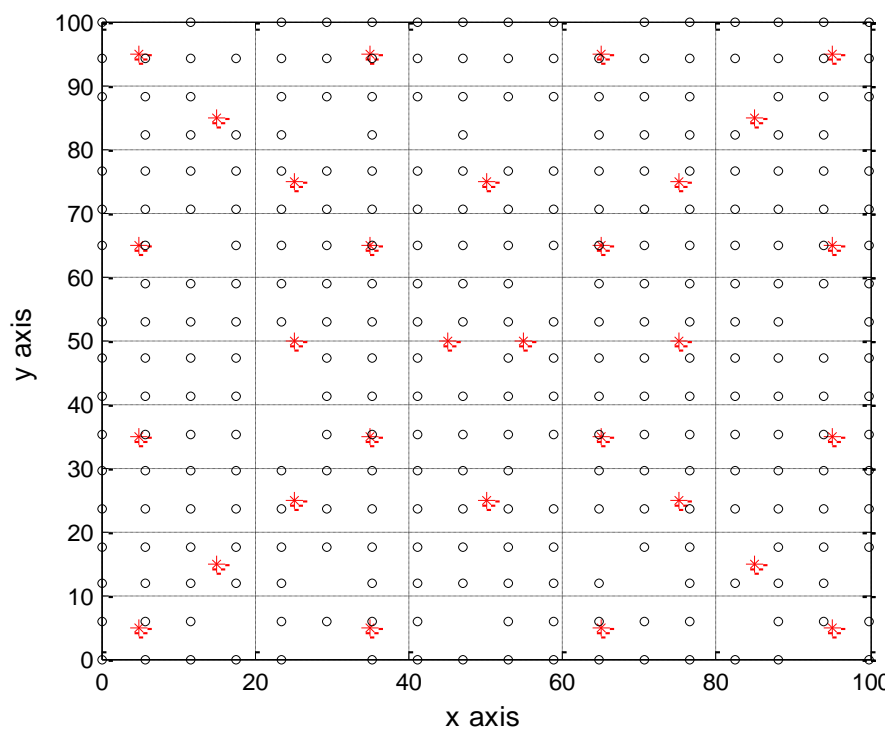

Red-Anchors, Black-Unknown

Figure 3. Square Regular Placement Model

For the presented deployment strategies, DV-HOP and APIT localization methods are implemented in the software.

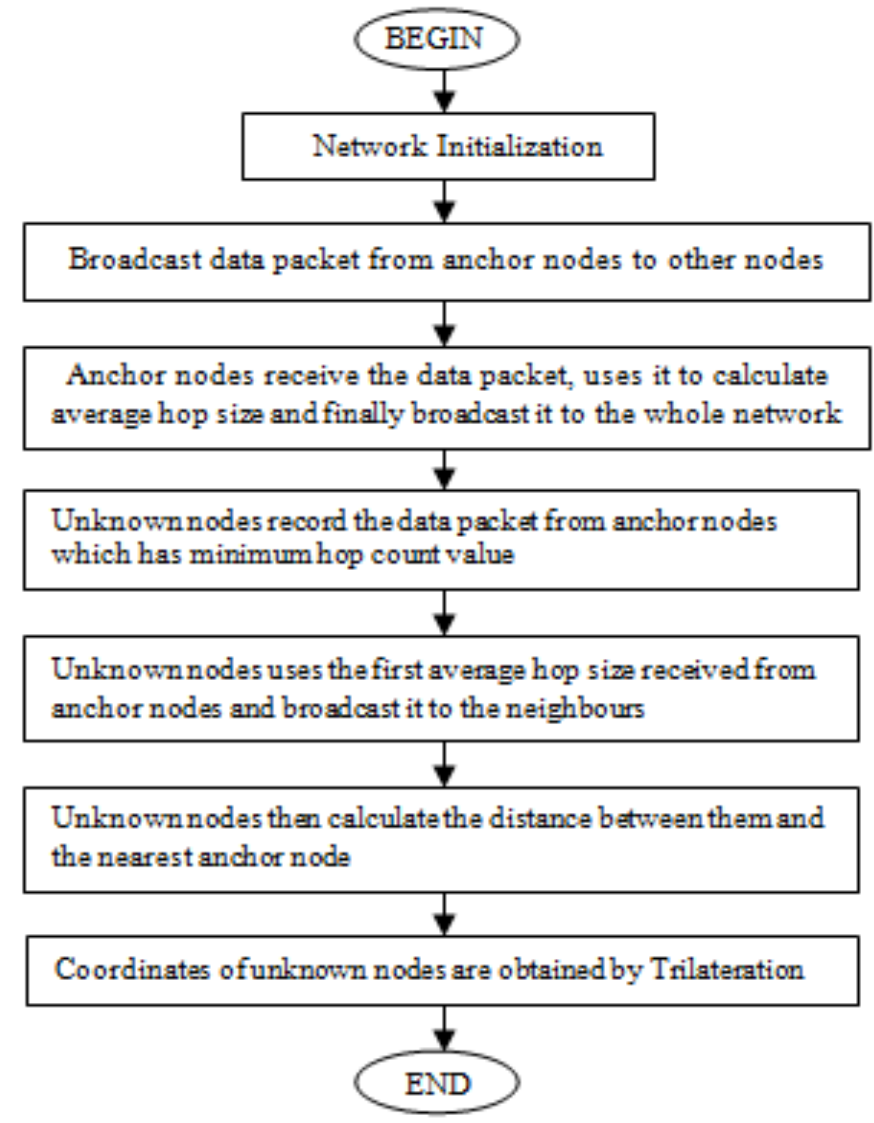

Figure 4. Flow Chart of DV-HOP Localization

Figure 4 shows the working of DV-HOP that after the network is initialised, the packets of information about the nodes are broadcasted to all nodes and then DVHOP algorithm is performed by calculating hop counts. 
Working of APIT is shown in the Figure 5 that neighbour information is calculated using RSS values and then test of triangulation is done to locate the nodes shown below:

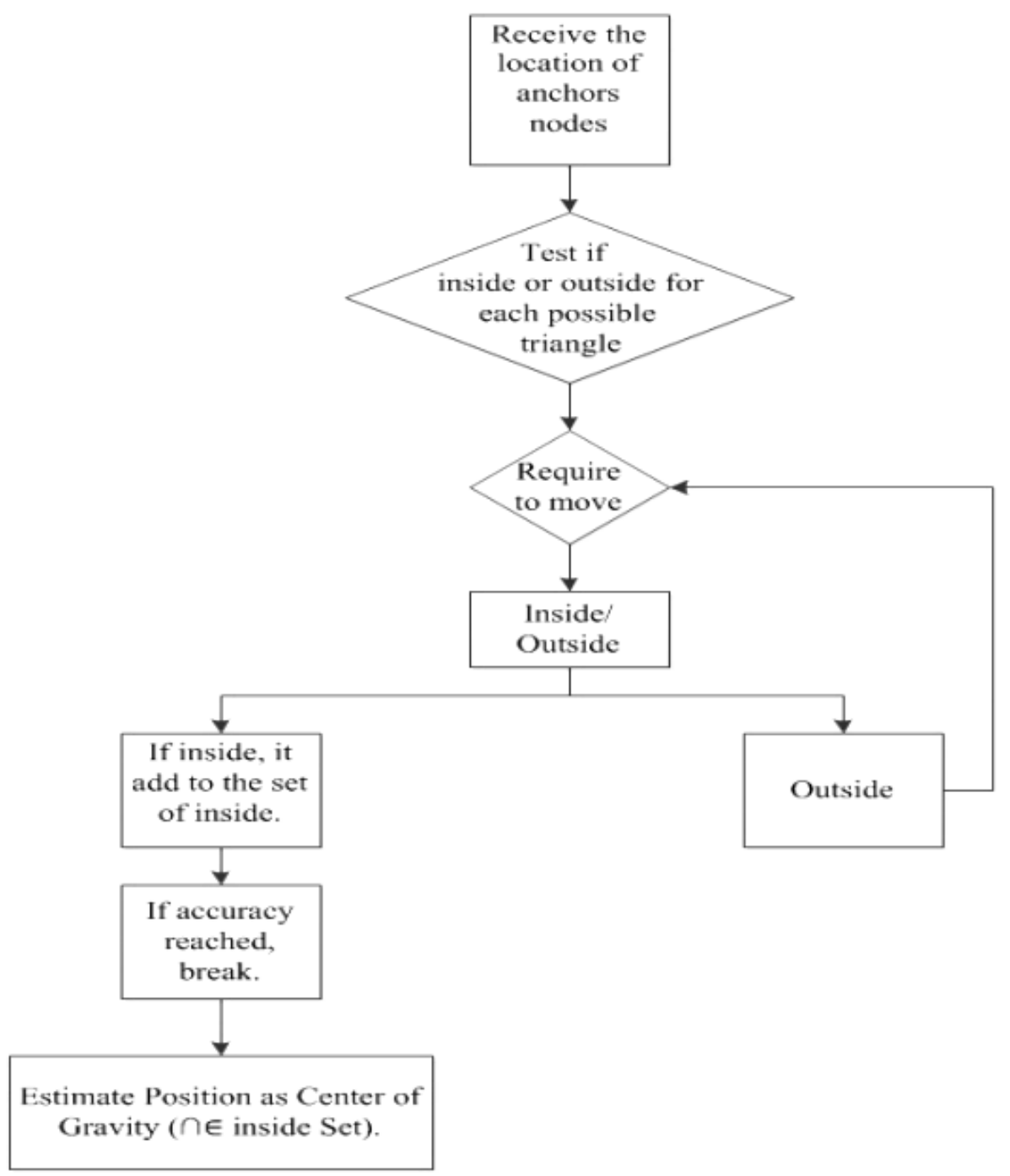

Figure 5. Flow Chart of APIT Algorithm

\subsection{Network Parameters}

In our experiments, we study several system-wide parameters that directly affect estimation error in the above two range-free localization algorithms. A description of these parameters follows:

2.2.3 Node Density (ND): Node density is defined as average number of nodes per node radio area.total number of nodes in the network are varied from 100 to 500.

2.2.4. Anchors Heard (AH): Average number of anchors heard by a node and used during estimation. More the anchors, better will be the accuracy. But number of anchors varies directly with the cost of network. Number of anchors are varied from 8 to 20 in our trials.

2.2.5. Anchor to Node Range Ratio (ANR): The average distance an anchor beacon travels divided by the average distance a regular node signal travels. When this value equals one, the anchor and nodes have the same average radio range. The larger this 
value, the fewer anchors required to maintain a desired $\mathrm{AH}$ value. We have taken value of this ratio from 1 to 5 .

\subsection{Performance Parameters}

The main purpose of these experiments is to find the ideal solution for localization error. Performance of DV-HOP localization technique is evaluated on the basis of localization error for location of unknown nodes.

Localization error is the difference between actual location of unknown nodes and calculated location of these nodes. Therefore, localization error is determined by Euclidean distance between actual and calculated values and is given by:

$$
E_{r}=\sqrt{\left(x-x^{\prime}\right)^{2}+\left(y-y^{\prime}\right)^{2}}
$$

Where $(x, y)=$ actual coordinates of unknown nodes and $\left(x^{\prime}, y^{\prime}\right)=$ calculated coordinates of unknown nodes.

Detail analysis of error is done using first and second order of error statistical tools considering different deployment strategies of anchors in a network:

\subsubsection{Mean Localization Error}

Mean of Localization error is first order error statistical tool. It is given by:

$$
\overline{E_{r}}=\frac{\sum E_{r}}{n}
$$

Where $E_{r}$ is Localization Error of each unknown node that is calculated using Eq. (1) and $\mathrm{n}$ is number of unknown nodes.

2.3.2. Cumulative Distribution Function (cdf): $C d f$ of a real valued random variable $X$ is given by

$$
F_{X} x=P(X \leq x)
$$

Where, $\mathrm{P}(\mathrm{X} \leq \mathrm{x})$ represents the probability that the random variable $\mathrm{X}$ takes a value less than or equal to $\mathrm{x}$. CDF of localization error is first order error statistical tool. It is used to know the probability of occurrence of mean error at each simulation under the graph. Here, we have evaluated CDF of all placement strategies to get the information of spread of mean error for a specified deployment strategy. Lesser the slope of curve lesser the spread hence more will be the efficiency of localization.

2.3.3. Dispersion of Error: The localization error for each node location estimation deviates from its mean value. The amount of variation is calculated through standard deviation. It is given by:

$$
\text { S.D. }=\sqrt{\frac{1}{n-1} \sum_{r=1}^{n}\left(E_{r}-\overline{E_{r}}\right)^{2}}
$$

Where, Er is error at each node localization, $\overline{E_{r}}$ is mean error at each simulation and $\mathrm{n}$ is number of simulations. Standard deviation is a measure used to quantify amount of variation or dispersion of error values.

\section{Performance Analysis of DV-HOP Technique}

DV-HOP is implemented in two placement models: Random placement and uniform placement model.

Results for random placement and uniform placement by varying different network parameters are as shown below: 


\subsection{Varying ANR}

From the Figure 6 and table 2, we observe that localization accuracy in random placement as well as in uniform placement doesn't show a fixed trend in response to variation in ANR but $A N R=1$ has the lowest value of all. So, in DV-Hop algorithm, the physical radio range of anchors is the same as that of target unknown nodes.So, the ANR is set to the distance an anchor beacon can propagate in units of node radio range (R).

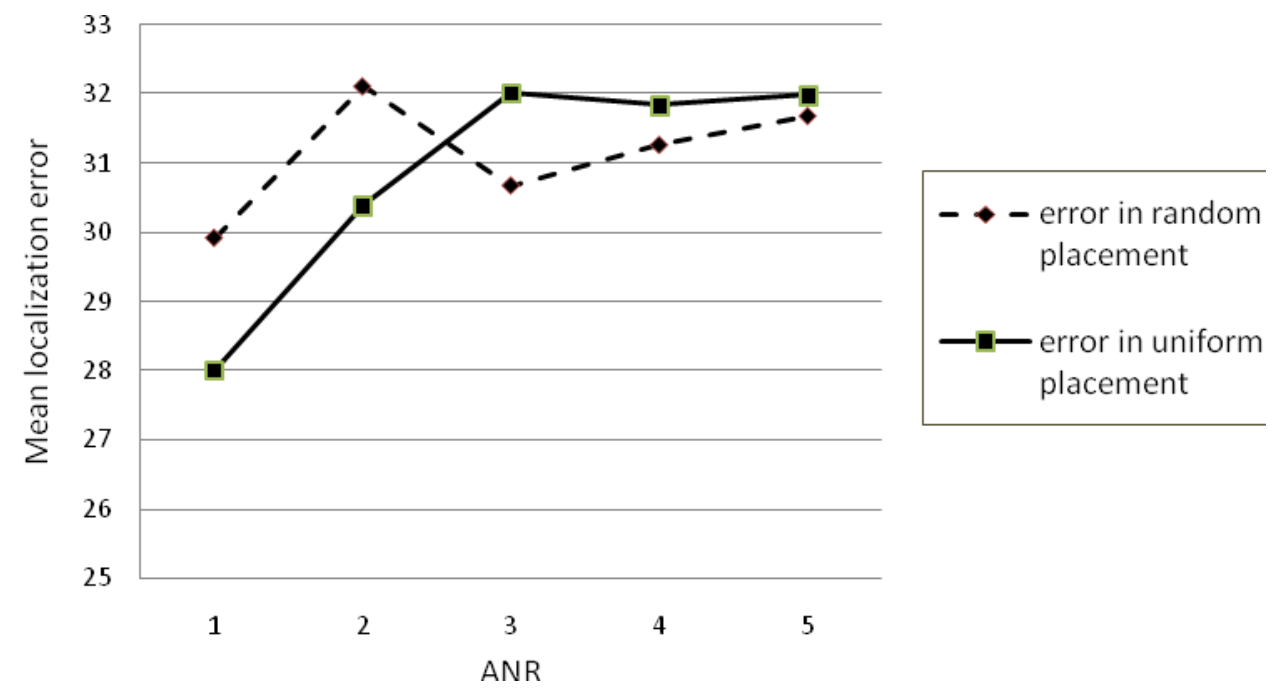

Figure 6. Comparison of Error by Varying ANR under Random and Uniform placement

Table 2. Error v/s ANR Values

\begin{tabular}{|c|c|c|}
\hline ANR & Error in random placement & Error in uniform placement \\
\hline 1 & 29.92 & 28.02 \\
\hline 2 & 32.12 & 30.39 \\
\hline 3 & 30.68 & 32.01 \\
\hline 4 & 31.27 & 31.83 \\
\hline 5 & 31.69 & 31.98 \\
\hline
\end{tabular}

\subsection{Varying Anchors}

The Figure 7 below shows that increasing the percentage of anchors improves the performance of localization but we have certain limits on the number of anchors in the network. More the anchors, more will be the hardware requirement and the energy consumed in the network and also more will be the cost of the network. So,in random placement we chose to have $10 \%$ anchor percentage in the sensor network. For this , radio range of 30-35 proved to be the best option with lower mean localization error as shown in the Figure 7 and table 3. 


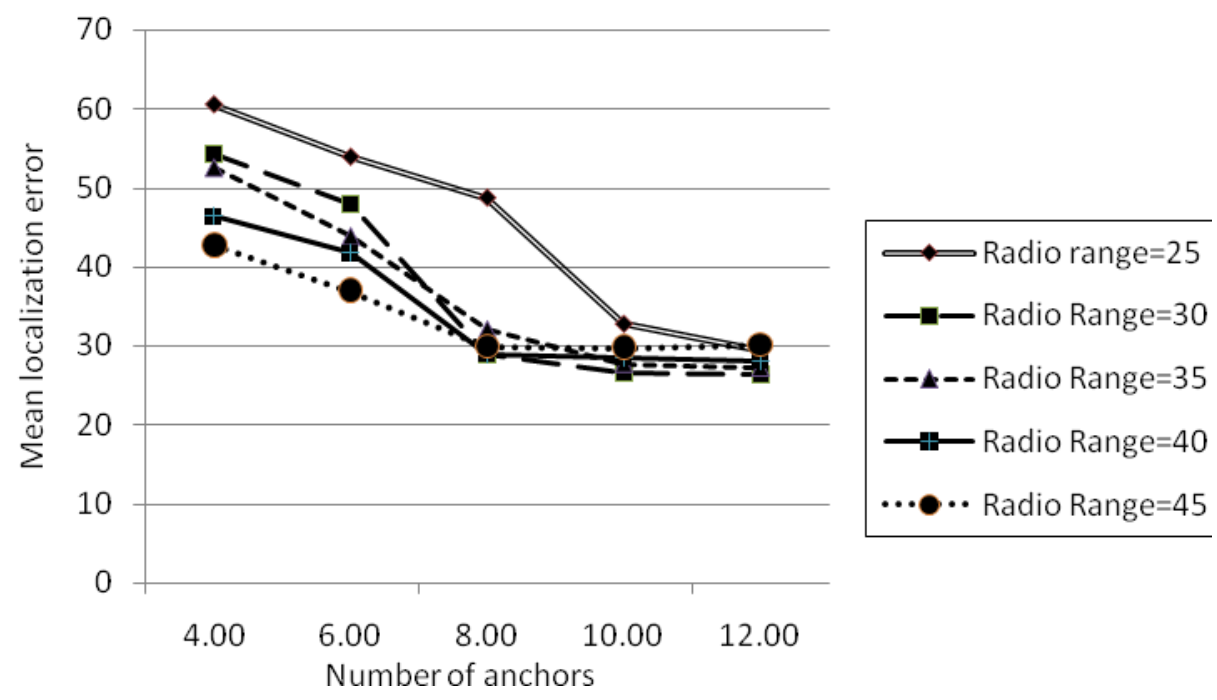

Figure 7. Mean Error by Varying Anchors at Different Radio Ranges (Random)

Table 3. Mean Error for Variation in Number of Anchors (Random)

\begin{tabular}{|l|l|l|l|l|l|}
\hline $\begin{array}{l}\text { Number of } \\
\text { Anchors }\end{array}$ & $\begin{array}{l}\text { Radio } \\
\text { range=25 }\end{array}$ & $\begin{array}{l}\text { Radio } \\
\text { Range=30 }\end{array}$ & $\begin{array}{l}\text { Radio } \\
\text { Range=35 }\end{array}$ & $\begin{array}{c}\text { Radio } \\
\text { Range=40 }\end{array}$ & $\begin{array}{l}\text { Radio } \\
\text { Range=45 }\end{array}$ \\
\hline 4 & 60.48 & 54.33 & 52.55 & 46.39 & 42.7 \\
\hline 6 & 53.87 & 47.97 & 43.86 & 41.76 & 36.89 \\
\hline 8 & 48.6988 & 28.9953 & 32.0553 & 29.0012 & 29.8454 \\
\hline 10 & 32.7831 & 26.6071 & 27.7247 & 28.5666 & 29.7172 \\
\hline 12 & 29.3798 & 26.3687 & 27.2341 & 28.1102 & 30.0974 \\
\hline
\end{tabular}

Further, in uniform placement model shown in Figure 8, localization error showed a decrease in value compared to random. But the trend of change in error hence the accuracy was the same as in random placement. Table 4 showed the details of the error achieved during variation in the number of anchors. From the Figure 8 , we observe that uniform placement is more reliable than random when $10 \%$ anchors are chosen in the network. Above $10 \%$ anchors, error is little lesser but other important constraints of hardware,energy consumed and the cost of network cannot be neglected. 


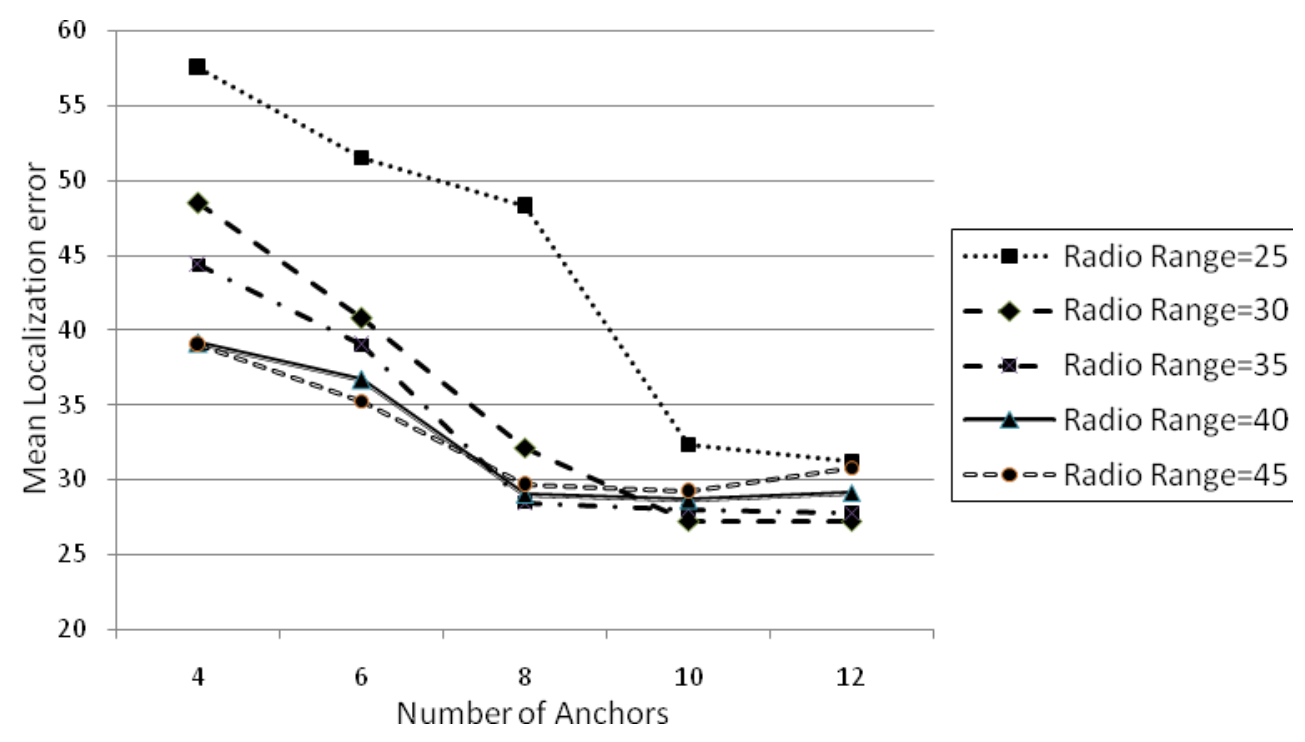

Figure 8. Mean Error by Varying Anchors using Uniform Placement

Table 4. Mean Error v/s Anchors at different Radio Ranges

\begin{tabular}{|l|l|l|l|l|l|}
\hline $\begin{array}{l}\text { Number of } \\
\text { anchors }\end{array}$ & $\begin{array}{l}\text { Radio } \\
\text { Range=25 }\end{array}$ & $\begin{array}{l}\text { Radio } \\
\text { Range=30 }\end{array}$ & $\begin{array}{l}\text { Radio } \\
\text { Range=35 }\end{array}$ & $\begin{array}{l}\text { Radio } \\
\text { Range=40 }\end{array}$ & $\begin{array}{l}\text { Radio } \\
\text { Range=45 }\end{array}$ \\
\hline 4 & 57.47 & 48.44 & 44.33 & 39.09 & 38.98 \\
\hline 6 & 51.53 & 40.75 & 38.98 & 36.64 & 35.23 \\
\hline 8 & 48.23 & 32.16 & 28.49 & 29.03 & 29.63 \\
\hline 10 & 32.33 & 27.22 & 27.98 & 28.64 & 29.19 \\
\hline 12 & 31.23 & 27.23 & 27.81 & 29.12 & 30.82 \\
\hline
\end{tabular}

\subsection{Varying Total Number of Nodes}

Figure 9 shows the result of increasing node density in the network. More the sensor nodes in the network, lesser will be the communication range of sensors required. Also, results become more reliable. But above 300 nodes, error starts increasing due to interference between nodes.

Table 5. Mean Error v/s Total Nodes at Different Radio Ranges(Random Placement)

\begin{tabular}{|l|l|l|l|l|l|}
\hline $\begin{array}{l}\text { Radio } \\
\text { Range }\end{array}$ & $\begin{array}{l}\text { Total } \\
\text { nodes=100 }\end{array}$ & $\begin{array}{l}\text { Total } \\
\text { nodes=200 }\end{array}$ & $\begin{array}{l}\text { Total } \\
\text { nodes=300 }\end{array}$ & $\begin{array}{l}\text { Total } \\
\text { nodes=400 }\end{array}$ & $\begin{array}{l}\text { Total } \\
\text { nodes=500 }\end{array}$ \\
\hline 12 & 87.887 & 85.667 & 44.675 & 45.3456 & 28.985 \\
\hline 15 & 50.3342 & 44.887 & 31.6846 & 26.98 & 26.6728 \\
\hline 20 & 38.9987 & 29.7048 & 27.6424 & 28.5842 & 29.8181 \\
\hline 25 & 28.9909 & 27.3317 & 28.9782 & 31.0427 & 32.51981 \\
\hline 30 & 28.8801 & 28.8068 & 29.8672 & 33.1481 & 33.2284 \\
\hline 35 & 27.7787 & 30.3086 & 33.0082 & 34.4759 & 35.421 \\
\hline 40 & 31.2234 & 32.0382 & 34.0828 & 35.9696 & 35.92 \\
\hline 45 & 32.7782 & 33.085 & 35.1975 & 37.887 & 38 \\
\hline
\end{tabular}




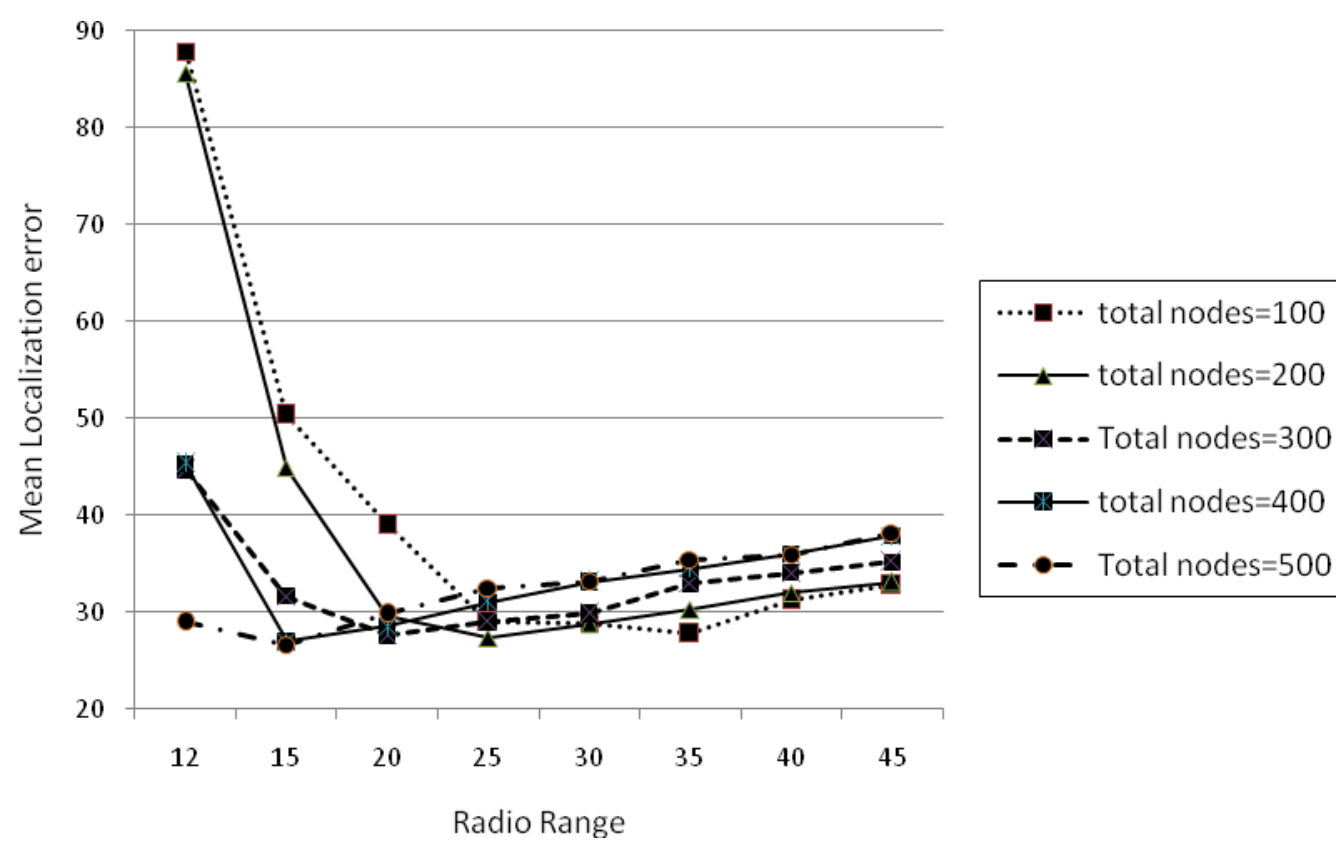

Figure 9. Mean Error varying Total Nodes (random placement)

Figure 10 shows the result of increasing total number of nodes in the network under uniform placement model.We can clearly understand that uniform model performed better than random by producing lesser error in the same conditions of network.

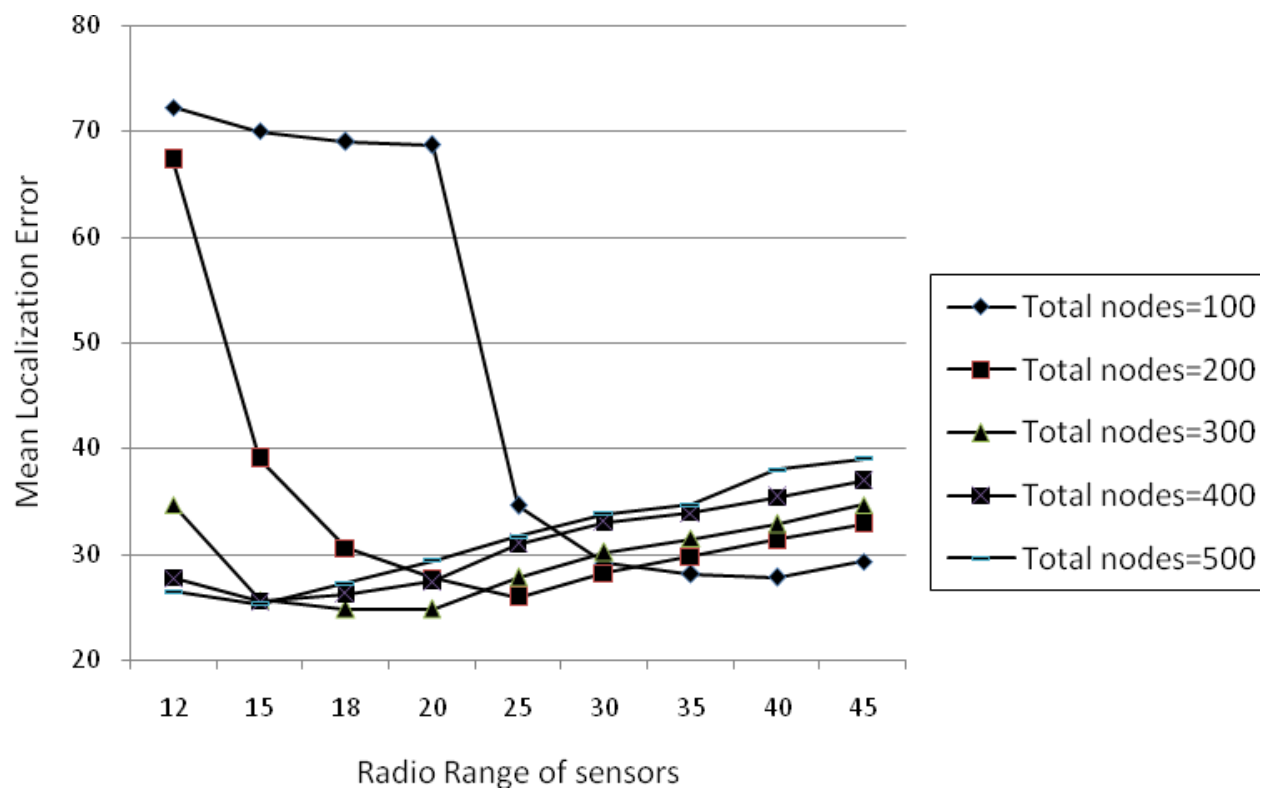

Figure 10. Mean Error Varying Total Nodes(uniform placement) 
Table 6. Mean Error Varying Total Nodes (uniform placement)

\begin{tabular}{|l|l|l|l|l|l|}
\hline $\begin{array}{l}\text { Radio } \\
\text { range }\end{array}$ & $\begin{array}{l}\text { Total } \\
\text { nodes=100 }\end{array}$ & $\begin{array}{l}\text { Total } \\
\text { nodes=200 }\end{array}$ & $\begin{array}{l}\text { Total } \\
\text { nodes=300 }\end{array}$ & $\begin{array}{l}\text { Total } \\
\text { nodes=400 }\end{array}$ & $\begin{array}{l}\text { Total } \\
\text { nodes=500 }\end{array}$ \\
\hline 12 & 72.262 & 67.242 & 34.6724 & 27.7369 & 26.4417 \\
\hline 15 & 69.9987 & 38.9826 & 25.6394 & 25.5456 & 25.2821 \\
\hline 18 & 68.9908 & 30.5343 & 24.7925 & 26.2466 & 27.2532 \\
\hline 20 & 68.6668 & 27.6957 & 24.8256 & 27.403 & 29.3555 \\
\hline 25 & 34.5719 & 25.8963 & 27.7928 & 30.9395 & 31.6948 \\
\hline 30 & 29.1206 & 28.2301 & 30.1838 & 32.9838 & 33.7979 \\
\hline 35 & 28.0855 & 29.7911 & 31.4662 & 33.876 & 34.6542 \\
\hline 40 & 27.8125 & 31.3574 & 32.8282 & 35.3643 & 37.9876 \\
\hline 45 & 29.266 & 32.8695 & 34.6755 & 36.9879 & 39.0065 \\
\hline
\end{tabular}

So, we conclude that DV-HOP performs better in uniform placement model with $10 \%$ anchors in the network i.e. 30 anchors and 300 total nodes gives a reliable DV-HOP localization system as shown in figure 10 and table 6 .

Cummulative distributive function is used as first order error analysis tool.

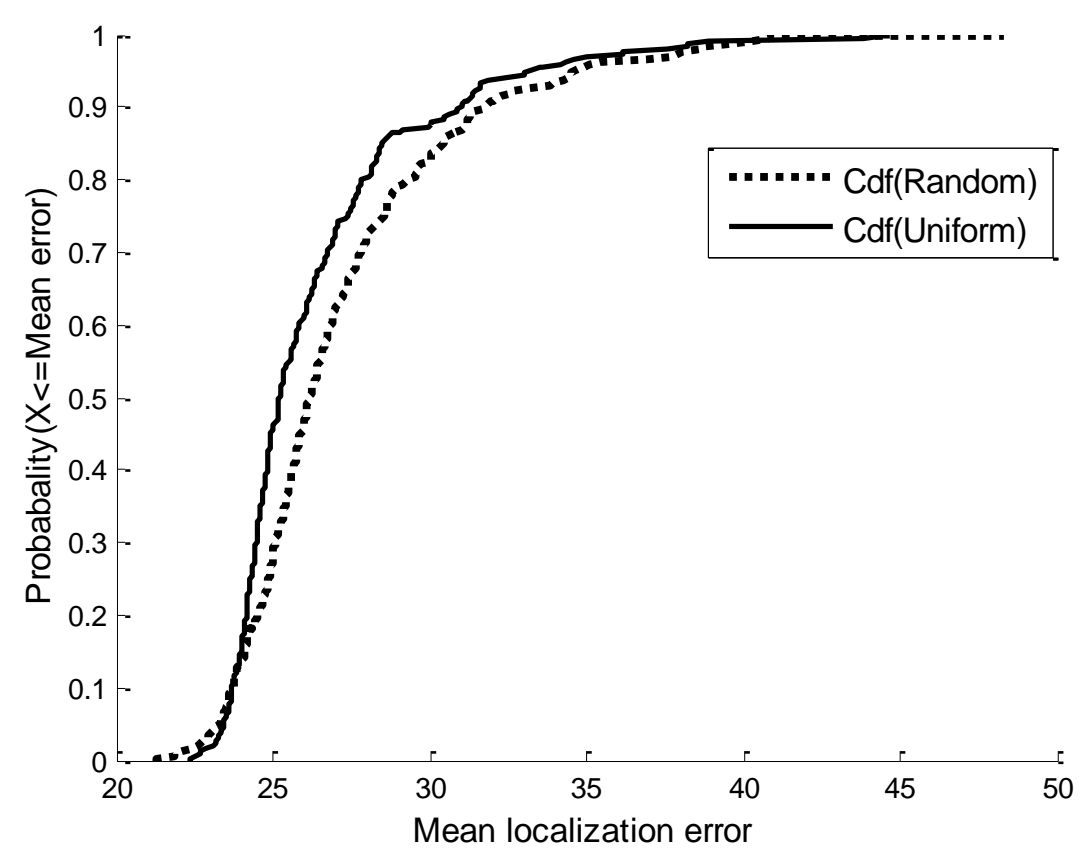

Figure 11. Cdf Graph between Errors for Random and Uniform Placement

Figure 11 shows that cdf graph of uniform placement reaches its maximum value prior to random one. This shows that uniform placement has less uncertainity. Thus, making localization system more reliable.

\section{Performance Analysis of APIT Technique}

APIT technique is also implemented using two placement models: Random and Uniform 
ANR values variation, anchors and node density of the network affect the localization as is shown below in our experiments:

\subsection{Varying ANR}

Figure 12 and table 7 shows that as anchor to node radio range ratio increases from 1 to 3 ,the error decreases but from $\mathrm{ANR}=4$, it started increasing again. So, $\mathrm{ANR}=3$ is suitable for all the scenarios considered further.

Table 7. Mean Error Varying ANR(Random and Uniform)

\begin{tabular}{|l|l|l|}
\hline ANR & \multicolumn{1}{|c|}{$\begin{array}{c}\text { Mean Error } \\
\text { (Random) }\end{array}$} & $\begin{array}{c}\text { Mean Error } \\
\text { (uniform) }\end{array}$ \\
\hline 1 & 44.76 & 40.23 \\
\hline 2 & 38.29 & 37.28 \\
\hline 3 & 32.01 & 31.17 \\
\hline 4 & 34.99 & 32.91 \\
\hline 5 & 36.19 & 34.81 \\
\hline
\end{tabular}

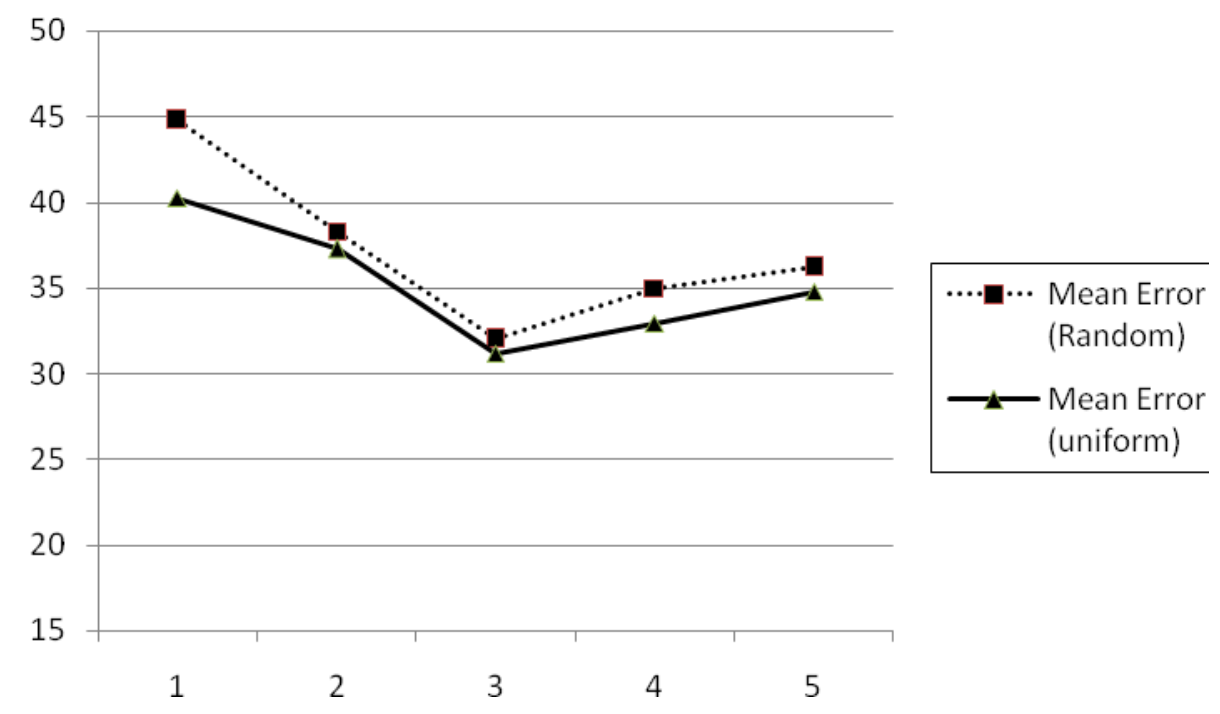

Figure. 12 Mean Error Varying ANR

\subsection{Varying Number of Anchors}

In Figure 13, we observe that in APIT, the mean localization error decreases with large difference as the anchors in the network are increased gradually.in random placement of nodes in the network APIT has shown better performance than DV-HOP as radio range range required by anchors and nodes respectively is very less .So, we finalise $10 \%$ anchors in the network to give desired results as shown in figure 13 and table 8. 
Table 8. Mean Error v/s Anchors (random)

\begin{tabular}{|l|l|l|l|l|l|}
\hline $\begin{array}{l}\text { Node-anchor } \\
\text { Radio Range }\end{array}$ & Anchors=4 & Anchors=6 & Anchors=8 & Anchors=10 & Anchors=12 \\
\hline 4,12 & 52.26 & 40.39 & 36.43 & 29.52 & 28.92 \\
\hline 5,15 & 42.19 & 37.17 & 30.01 & 28.71 & 29.59 \\
\hline 6,18 & 38.9 & 34.52 & 33.01 & 32.68 & 31.96 \\
\hline 8,24 & 38.29 & 34.71 & 35.15 & 33.37 & 34.01 \\
\hline 10,30 & 36.61 & 33.44 & 35.3 & 34.32 & 35.87 \\
\hline
\end{tabular}

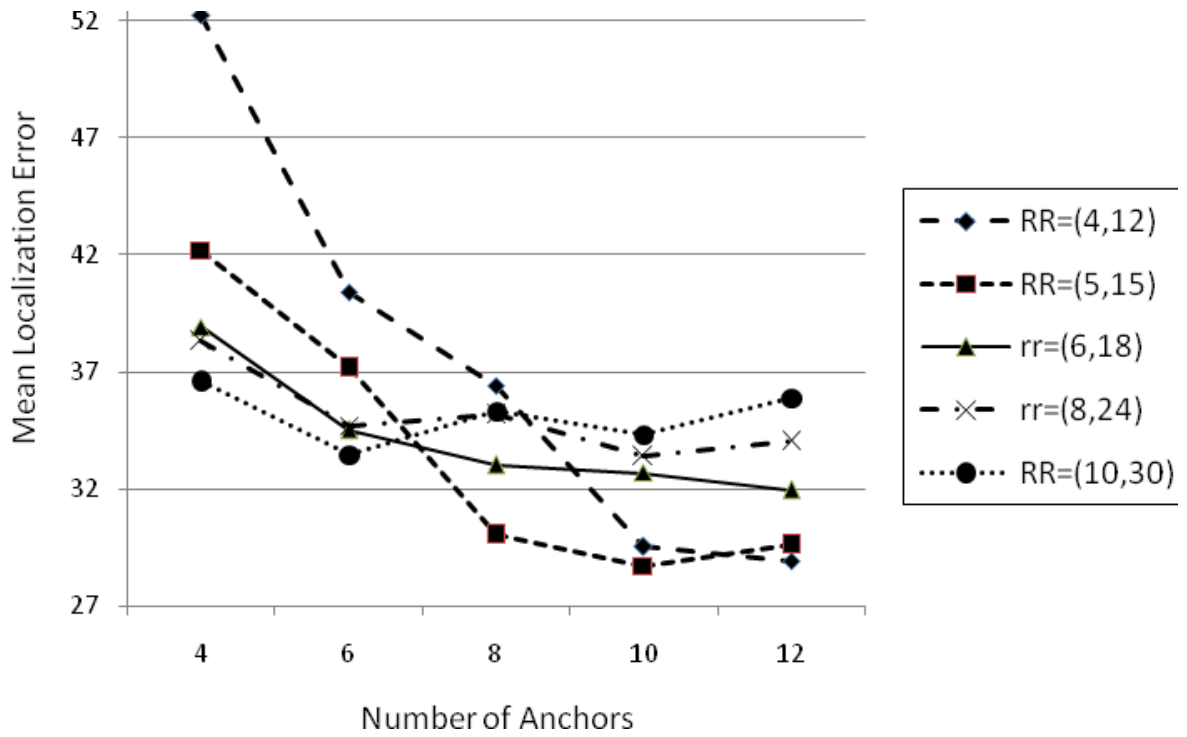

Figure 13. Mean Error Varying Anchors(random)

In uniform placement as shown in figure 14, variation in anchors quantity largely affects the the accuracy of network.As we increase the anchors, error is decreased. After $10 \%$ anchors, the decrease in the error i.e. increase in accuracy is not large enough to ignore hardware, energy consumption increase due to increase in the number of anchor.So, $10 \%$ anchors gave desired results in the network under uniform placement.

Table 9. Mean Localization Error v/s Anchors (Uniform)

\begin{tabular}{|l|l|l|l|l|l|}
\hline $\begin{array}{l}\text { Node-Anchor } \\
\text { Radio Range }\end{array}$ & Anchors=4 & Anchors=6 & Anchors=8 & Anchors=10 & Anchors=12 \\
\hline 4,12 & 50.45 & 39.34 & 30.02 & 29.35 & 29.01 \\
\hline 5,15 & 35.21 & 33.34 & 28.95 & 27.62 & 27.09 \\
\hline 6,18 & 38.01 & 35.74 & 33.38 & 32.26 & 30.63 \\
\hline 8,24 & 38.9 & 35.74 & 34.07 & 34.66 & 31.56 \\
\hline 10,30 & 41.2 & 37.9 & 35.21 & 34.19 & 34.63 \\
\hline
\end{tabular}




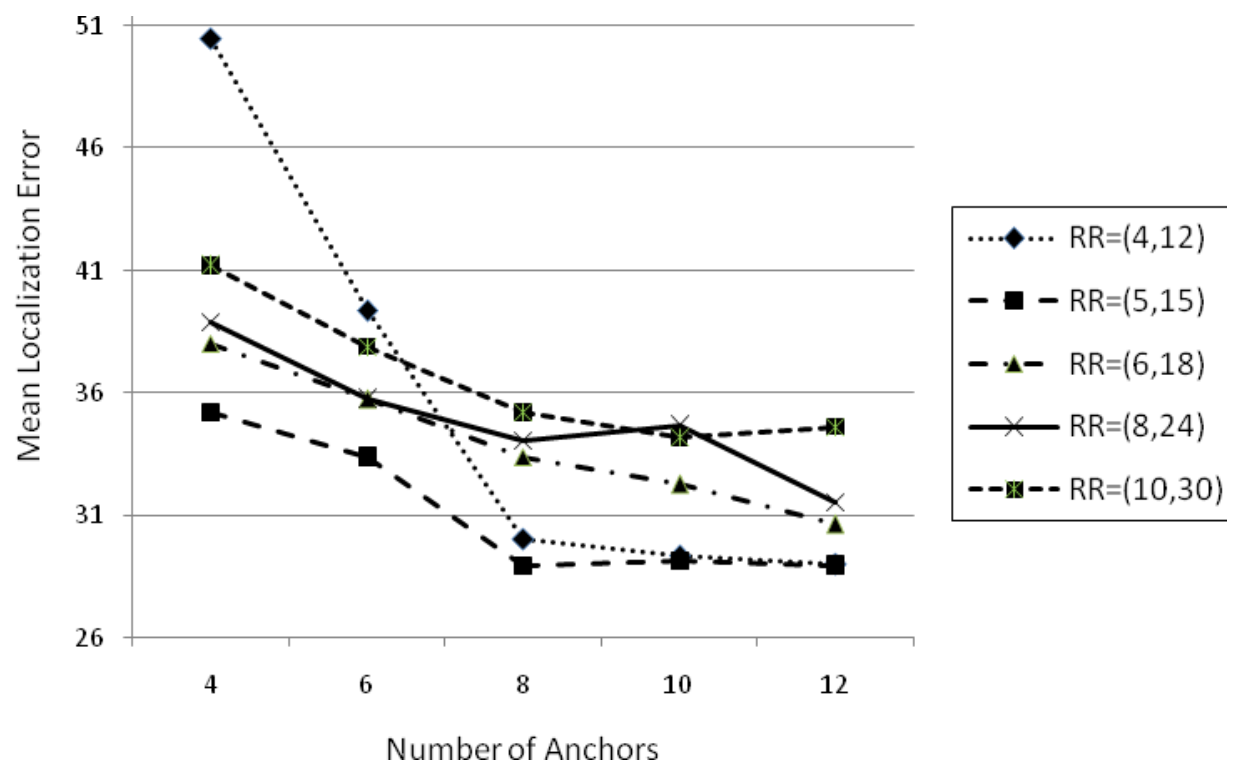

Figure 14. Mean Error Varying Anchors(uniform)

\subsection{Varying Total Number of Nodes}

Figure 15 depicts that higher sensor node density in the network results in lesser localization error. Hence, reliability on network increases if the network is denser. But this trend follows an increasing graph above 300 nodes in 100x100 square area of network. In Random placement, mean error shows the increasing trend at higher ardio ranges as it can settle with lesser error at low radio ranges when the network is dense as shown in table 9.

Table 9. Mean Error v/s Total Nodes

\begin{tabular}{|l|l|l|l|l|l|}
\hline $\begin{array}{l}\text { Node- } \\
\text { Anchor } \\
\text { radio range }\end{array}$ & $\begin{array}{l}\text { Total } \\
\text { nodes=100 }\end{array}$ & $\begin{array}{l}\text { Total } \\
\text { nodes=200 }\end{array}$ & $\begin{array}{l}\text { Total } \\
\text { nodes=300 }\end{array}$ & $\begin{array}{l}\text { Total } \\
\text { nodes=400 }\end{array}$ & $\begin{array}{l}\text { Total } \\
\text { nodes=500 }\end{array}$ \\
\hline 3,9 & 39.92 & 36.93 & 22.99 & 17.47 & 15.11 \\
\hline 4,12 & 37.15 & 22.07 & 22.87 & 24.35 & 28.9 \\
\hline 5,15 & 28.91 & 31.89 & 33.92 & 33.98 & 42.71 \\
\hline 6,18 & 32.78 & 35.52 & 37.9 & 39.82 & 47.3 \\
\hline 8,24 & 34.09 & 35.99 & 38.38 & 40.34 & 47.55 \\
\hline 10,30 & 37.89 & 36.95 & 42.37 & 48.57 & 49.17 \\
\hline
\end{tabular}




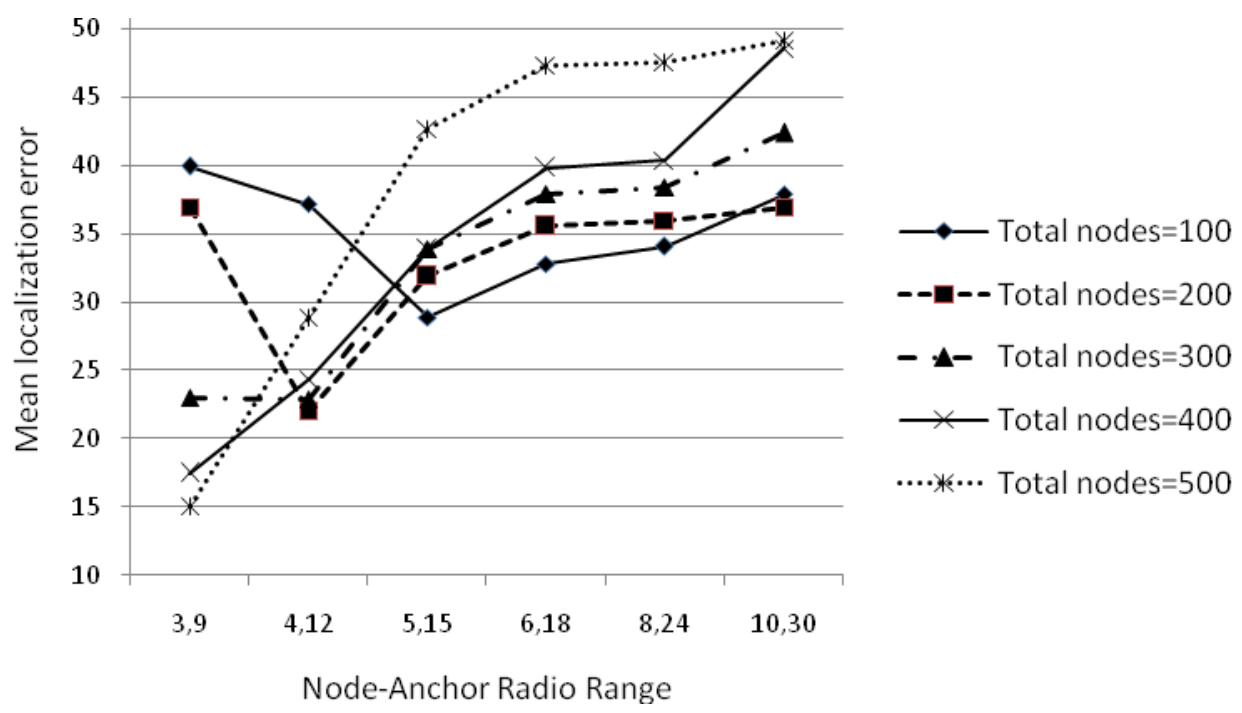

Figure 15. Mean Error Varying Total Nodes (random)

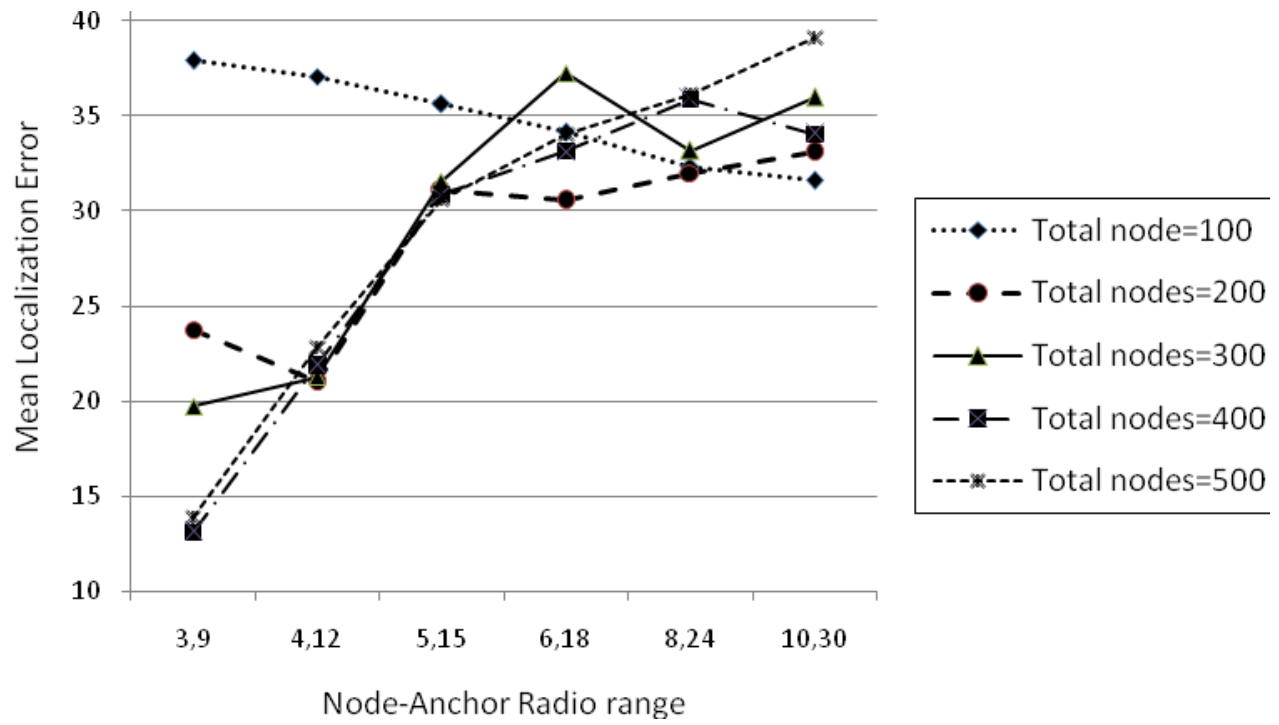

Figure 16. Mean Error Varying Total Nodes(uniform)

Table 12. Mean Error Varying Total Nodes(uniform)

\begin{tabular}{|l|r|r|r|l|r|}
\hline $\begin{array}{l}\text { Node-Anchor } \\
\text { radio range }\end{array}$ & $\begin{array}{l}\text { Total } \\
\text { nodes=100 }\end{array}$ & $\begin{array}{l}\text { Total } \\
\text { nodes=200 }\end{array}$ & $\begin{array}{l}\text { Total } \\
\text { nodes=300 }\end{array}$ & $\begin{array}{l}\text { Total } \\
\text { nodes=400 }\end{array}$ & $\begin{array}{l}\text { Total } \\
\text { nodes=500 }\end{array}$ \\
\hline 3,9 & 37.89 & 23.77 & 19.75 & 13.13 & 13.91 \\
\hline 4,12 & 37.09 & 21 & 21.29 & 21.89 & 22.82 \\
\hline 5,15 & 35.61 & 31.06 & 31.57 & 30.86 & 30.6 \\
\hline 6,18 & 34.12 & 30.55 & 37.25 & 33.15 & 34.02 \\
\hline 8,24 & 32.3 & 32 & 33.18 & 35.88 & 36.12 \\
\hline 10,30 & 31.61 & 33.09 & 35.96 & 34.04 & 39.14 \\
\hline
\end{tabular}


In uniform placement model shown in Figure 11 and table 10, the accuracy of network is significantly increased with increase in the total nodes placed in the network. Due to increase in error at 400 and 500 nodes, we chose a network with uniform placement and 300 total nodes of which 30 are anchors as desired network for APIT to work properly as shown in Figure 11 below.

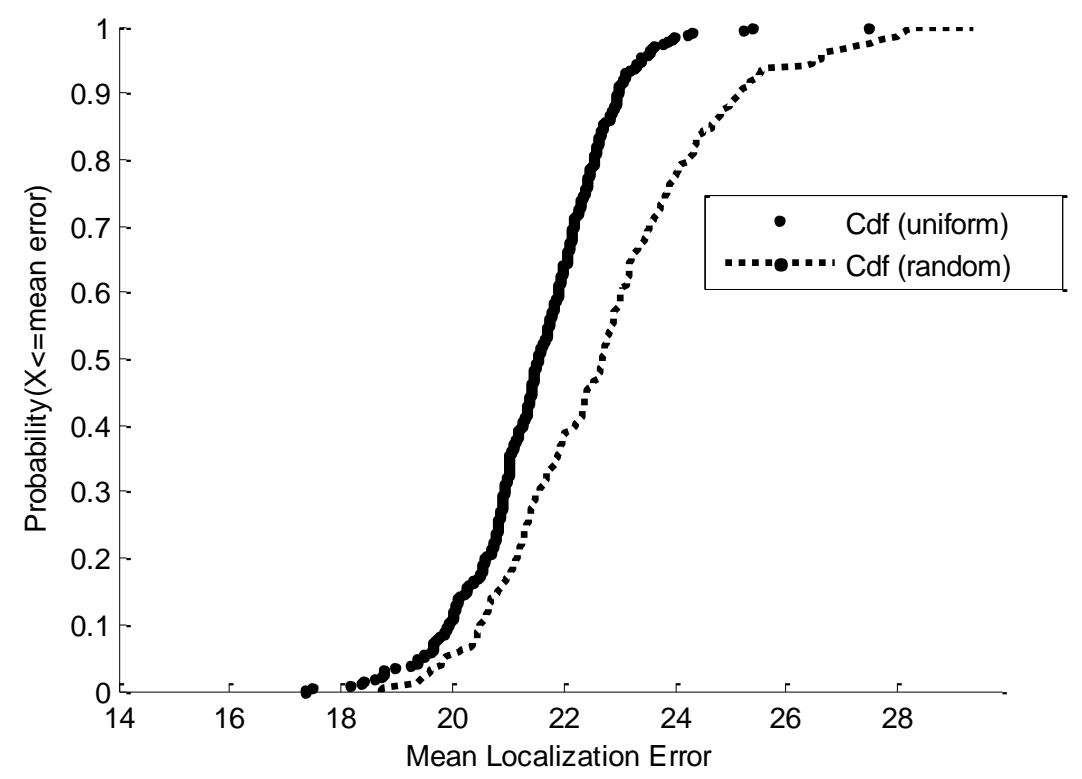

Figure 17. APIT Cdf (Random v/s Uniform)

From the Figure 12 above, it is clear that uniform placement error has very less slope.this means that APIT uniform is better than random.

\section{Performance Comparison of DV-HOP and APIT Localization Algorithms}

In the above sections, we have done detail analysis of APIT and DV-HOP localization system. Individually both the schemes satisfy to almost same network scenario.So, we will compare both the schemes on the basis of their best scenarios chosen i.e. uniform placement, 300 total nodes and 30 anchors.

We propose a regular placement of anchors to get better results. The observation is explained below:

DV-HOP produces localization error of 22.34 in the network of 300 nodes and 30 anchors and used radio range of 13 units whereas APIT gave error of 21.03 with nodeanchor radio range of just (4-12) units. To approve our results, we will further use first order and second order statistical tools to anlyse the localization error.

Figure 18 compares DV-HOP and APIT accuracy by using Cdf of error. We observe that APIT reaches the maximum value at very early stage as compared to DV-HOP.This means that uncertainity of error in APIT is lesser than DV-HOP making it more reliable system than DV-HOP. 


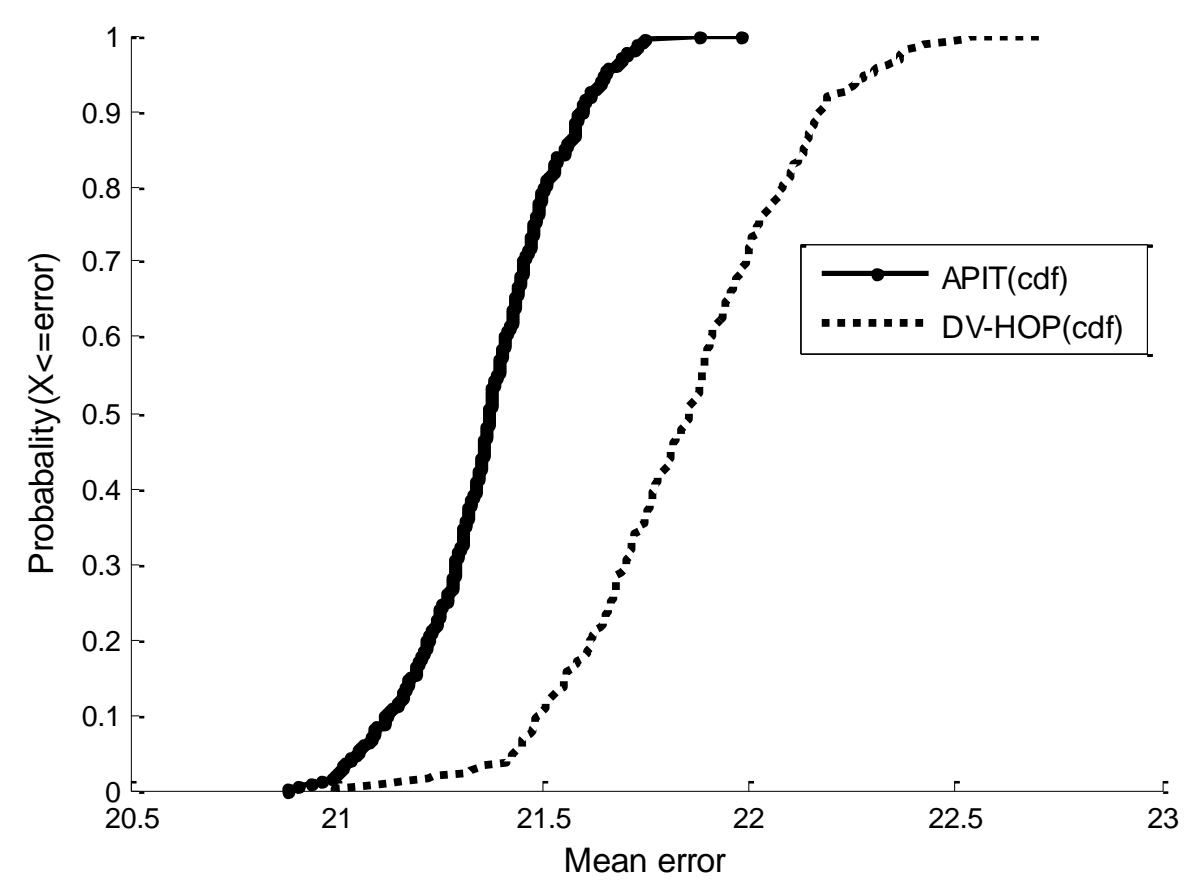

Figure 18.Cdf Comparison of APIT and DV-HOP (regular placement)

Further standard deviation is second order error analytical tool used to check the dispersion of error. More the dispersion more will be the unreliability. So, graph with lesser dispersion is better i.e APIT is better than DV-HOP as shown in Figure 19.

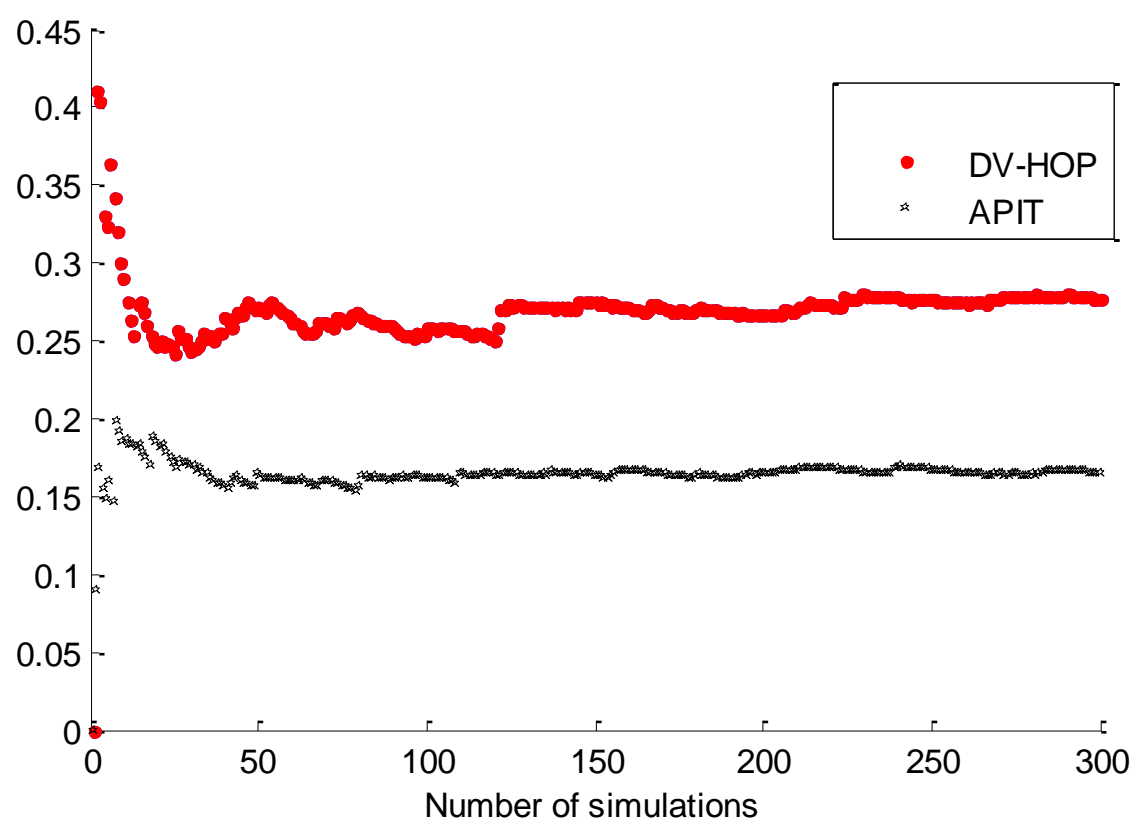

Figure 19. Standard deviation of DV-HOP v/s APIT 


\section{Conclusion}

In this paper ,results and analysis of implementation of DV-HOP and APIT localization techniques have been shown under different scenarios by considering several network parameters. We have concluded that uniform placement of nodes gave better results than random placement.Further, we proposed square regular placement of anchors so that they are at the reach of all nodes. We observe a large improvement in the performance of both the techniques. Finally APIT showed better performance than DV-HOP in the structured deployment of anchors in the network on the basis of accuracy obtained during localization..

\section{References}

[1] D. Niculescu and B. Nath, "DV Based Positioning in Ad Hoc Networks", Telecommunication Systems, vol. 22, no. 1-4, (2003), pp. 267-280.

[2] D. Niculescu and B. Nath, "Ad-hoc positioning system. Proceedings of the Global Telecommunications Conference, (2001), pp. 2926- 2931.

[3] J. Yick, B. Mukherjee and D. Ghosal, "Department of Computer Science", University of California, Davis, CA 95616, United States, Wireless sensor network survey, Computer Networks, vol. 52, (2008), pp. 2292-2330

[4] G. Mao, B. Fidan and B. Anderson, "Wireless sensor network localization techniques", vElsevier/ACM Computer Networks, vol. 51, (2007), pp. 2529-2553.

[5] G. S. Klogo and J. D. Gadze, "Energy Constraints of Localization Techniques in Wireless Sensor Networks (WSN): A Survey", International Journal of Computer Applications (0975 8887), vol. 75, no. 9, (2013), pp. 44.

[6] J. Z. Wang and H. Jin, "Improvement on APIT Localization Algorithms for Wireless Sensor Networks", IEEE international Conference on Network Security, Wireless Communications and Trusted Computing, (2009), pp. 719-723.

[7] T. He, C. Huang, B. M. Blum, J. A. Stankovic and T. Abdelzaher, "Range-free localization schemes for large scale sensor networks", Proceedings of the 9th ACM Annual International Conference on Mobile Computing and Networking (MobiCom'03), (2003), pp. 81-95.

[8] S. Singh, R. Shakya and Y. Singh, "Department of Computer Science, Ideal Institute of Technology, Ghaziabad", Localization Techniques in Wireless Sensor Networks, International Journal of Computer Science and Information Technologies, vol. 6, no. 1, (2015), pp. 844-850.

[9] N. Patwari, J. N. Ash, S. Kyperountas, A. O. Hero III, R. L. Moses and N. S. Correal, "Locating the Nodes", Cooperative localization in wireless sensor networks, IEEE SIGNAL PROCESSING MAGAZINE, (2005), pp. 1053- 5888/05/\$20.00@2005IEEE.

[10] T. S. Rappapport, "Wireless Communications: Principles and Practice", Prentice Hall: New Jersey, IEEE Press, (1996), pp. 50-143.

[11] J. Zheng and A. Jamalipour, "Wireless sensor Networks", A networking perspective, A John Wiley \& Sons, Hoboken, New Jersey, USA, (2009), pp. 276-313.

[12] F. Viani, L. Lizzi and P. Rocca, "Object Tracking through RSSI Measurements in Wireless Sensor Networks", Electronics Letters, vol. 44, no. 10, (2008), pp. 653- 654. 